Document downloaded from:

http://hdl.handle.net/10251/150417

This paper must be cited as:

Bendito, A.; Romero, ML.; Bonet Senach, JL.; Miguel Sosa, P.; Fernández Prada, MÁ. (2009). Inelastic Effective Length Factor of Nonsway Reinforced Concrete Columns. Journal of Structural Engineering. 135(9):1034-1039. https://doi.org/10.1061/(ASCE)07339445(2009)135:9(1034)

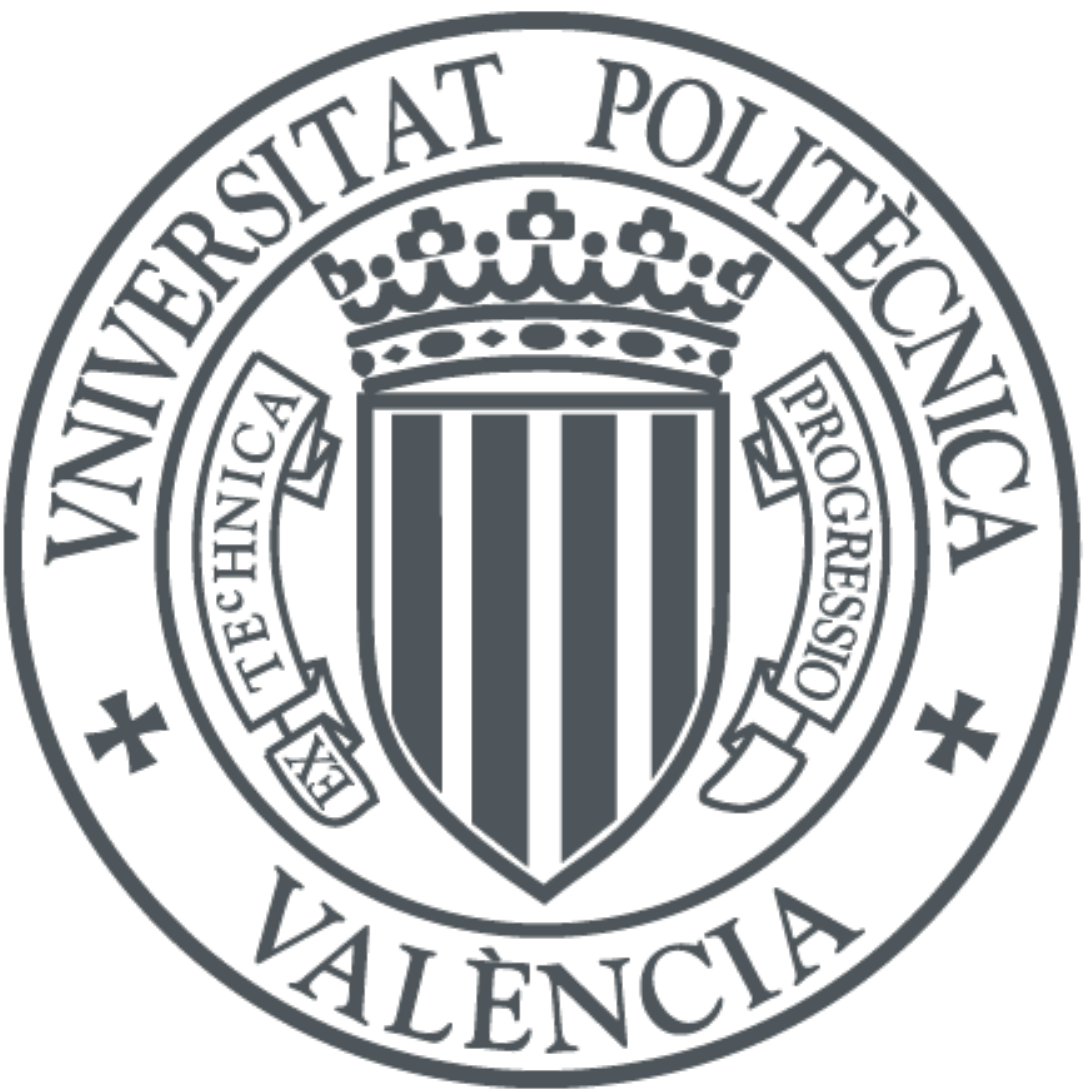

The final publication is available at

https://doi.org/10.1061/(ASCE)0733-9445(2009)135:9(1034)

Copyright American Society of Civil Engineers

Additional Information 


\title{
Inelastic effective length factor of non-sway reinforced concrete columns
}

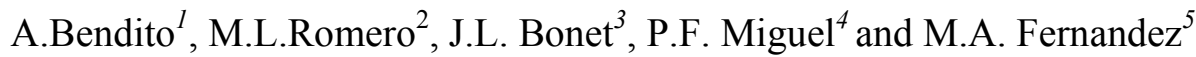

\section{ABSTRACT}

This paper proposes a new equation for the effective length factor (k-factor) for reinforced concrete columns in braced frames. The new formula is valid both for normal and high strength concrete. The equation was obtained from a sensitivity analysis performed on a 2-D nonlinear finite element numerical model that takes into account the inelastic behavior of the concrete columns (cracking, yielding, and second order effects). The numerical model was calibrated with 44 experimental tests performed by the authors's research group. A comparative study was carried out between the numerical model and different national design codes, displaying important differences with respect to all of them: the ACI code (from $37 \%$ to $-3 \%$ ), the Spanish code EHE (from $26 \%$ to $-9.26 \%$ ) and the Euro code 2 (from $14 \%$ to $-14 \%$ ). It was decided to propose two additional simplified equations: one for checking and the second for design.

SUBJECT HEADINGS: Effective length, Buckling, Columns, Reinforced concrete, Inelasticity

\footnotetext{
${ }^{1}$ Assist. Prof., PhD, Engineering Dpt., Núcleo Universitario Rafael Rangel, Universidad de Los Andes, Venezuela : americab@ula.ve

${ }^{2}$ Assoc. Prof., PhD, Instituto de Ciencia y Tecnologia del Hormigon, Univ. Politécnica de Valencia, 46022 Valencia, Spain.(corresponding author) E-mail: mromero@mes.upv.es

${ }^{3}$ Assoc. Prof., PhD, Instituto de Ciencia y Tecnologia del Hormigon, Univ. Politécnica de Valencia, 46022 Valencia, Spain. E-mail: jlbonet@cst.upv.es

${ }^{4}$ Prof., PhD, Instituto de Ciencia y Tecnologia del Hormigon, Univ. Politécnica de Valencia, 46022 Valencia, Spain. E-mail: pmiguel@cst.upv.es

${ }^{5}$ Prof.,PhD, Instituto de Ciencia y Tecnologia del Hormigon, Univ. Politécnica de Valencia, 46022 Valencia, Spain. E-mail: mafernan@cst.upv.es
} 


\section{INTRODUCTION}

The evaluation of the effective length factor (k-factor) in real concrete columns is not properly studied at the present time. This is due to the fact that most of the equations to obtain such factor are developed assuming a linear elastic material behavior or a reduced stiffness E-I of the column, which is far from the real behavior of reinforced concrete columns, where the strength of concrete, the reinforcement ratio, the slenderness and the stiffness of the joints have an important effect on the curvature of the support.

As is well known, the k-factor transforms the buckling of a column with different stiffness restraints at the ends in the buckling of another equivalent pinned-pinned column with an effective buckling length $\left(\mathrm{L}_{\mathrm{eff}}=\mathrm{k} \cdot \mathrm{L}\right)$. The differential equations of both problems have been widely solved for an elastic material, Duan and Chen (1999), and they are implemented in the national design codes (both for steel or concrete structures) through the use of simplified equations of the effective length factor or the well-known alignment charts.

Typically the k-factor depends on the relative stiffness of the joints $\Psi \mathrm{i}$, also called "end restrain factor" (the sum of the column stiffness divided by the sum of beam stiffness). This factor is used in the American code ACI (2005) or the Spanish EHE (2001), which can very from zero to infinite.

$$
\Psi_{i}=\frac{\sum\left(\frac{E I}{L}\right)_{\text {columns }}}{\sum\left(\frac{E I}{L}\right)_{\text {beams }}}
$$

But Aristizabal-Ochoa (1994) proposed a "fixity factor" $\left(\rho_{\mathrm{i}}\right)$ that varies from zero to one: 


$$
\left\{\begin{array} { l } 
{ \rho _ { 1 } = \frac { 1 } { 1 + \frac { 3 } { R _ { 1 } } } } \\
{ \rho _ { 2 } = \frac { 1 } { 1 + \frac { 3 } { R _ { 2 } } } }
\end{array} \left\{\begin{array}{l}
R_{1}=\frac{K_{1}}{\left(\frac{E_{c} \cdot I_{g}}{L}\right)} \\
R_{2}=\frac{K_{2}}{\left(\frac{E_{c} \cdot I_{g}}{L}\right)}
\end{array}\right.\right.
$$

where

$\mathrm{E}_{\mathrm{c}}=$ elastic modulus of concrete

$\mathrm{I}_{\mathrm{g}}=$ gross moment of inertia of the column section

$\mathrm{L}=$ unsupported length of the column

$\mathrm{K}_{1}$ and $\mathrm{K}_{2}$ : stiffness of each spring (end restraint condition). These springs represent the stiffness of the two beams and the exterior column that arrive to the joint. Typically EI and $\mathrm{K}_{1}$ and $\mathrm{K}_{2}$ are considered elastic.

Both the end restraint factors and fixity factor result in the same effective length factor because they are the solutions to the same differential equation in the elastic range, but use different nomenclature. The elastic k-factor for non-sway columns varies from 0.5 (clamped-clamped) to 1 (pinned-pinned).

For reinforced concrete structures there were a lot of studies in the elastic range regarding the design of slender columns. Cranston (1972) proposed simplified equations for the effective length factor. Also, a lot of work studying the influence of different end restraint conditions was completed by Hu et al. (1993) and Duan et al (1993) who proposed a new equation based on the partial fraction model.

\section{$\underline{\text { Inelastic Behavior }}$}

Moreover, the theoretical problem of inelastic buckling was pointed out long time ago with the tangent elastic modulus theory and employing the reduced modulus theory or the Shanley's theory, Shanley (1946). 
For steel structures, Yura (1971) and Disque (1973) presented an inelastic k-factor method for steel structures using the concept of tangent elastic modulus; employing the same alignment charts but modifying the end restrains factors.

Besides, the problem for reinforced concrete structures has not been deeply studied, although MacGregor at al. (1970) and Breen et al. (1972) pointed out the necessity to get deeper in this subject. A simple but good manner to include the inelastic behavior of beams and columns is the one implemented in the ACI code (2005), where the stiffness of beams and columns for calculating the end restraint factor is reduced using a fixed factor (i.e. for columns $\mathrm{EI}=0.7 \mathrm{E}_{\mathrm{c}} \mathrm{I}_{\mathrm{g}}$ ).

But the influence of the k-factor on the behavior of reinforced concrete structures is dependent on the strength of concrete, Broms and Viest (1961), the slenderness, the fixity factors and the steel reinforcement ratio because they contribute to the non-linearity of the column. Moreover, if a column is cracked or yielded, its stiffness is lower than the elastic one. In this case the k-factor will be lower than the elastic one. Conceptually this makes sense because it is as though the rotational springs are relatively more rigid, having a tendency toward the behavior of the clamped-clamped column (for which the elastic $\mathrm{k}$ is 0.5 ).

With the actual sophistication of the numerical models, the concrete can be modeled closer each time to the real behavior. Thereupon, Bazant and Xiang (1997) studied the inelastic buckling of concrete columns in braced frames but focused the study to improve the method of analysis and not to obtain the k-factor. They assumed a sine curve as the deflection curve of the column and implemented all the non-linearities of concrete. The improvement consisted in considering the wavelength as unknown and variable during loading. Conceptually this is the same as the effective length factor. Later, Furlong (1998) discussed about the interest for practitioners to include a very complex method (although more realistic) in the codes. 
Moreover, concrete technology has been improved considerably and now high strength concrete (HSC) can be easily obtained, whose mechanical behavior cannot be extrapolated simply from that of normal strength concrete (NSC). The different simplified methods that can be used for analysis in failure for slender columns therefore need to be checked, so that their application might be extended to HSC from NSC.

The objective of this paper is therefore to establish an improved $\mathrm{k}$-factor equation which includes the complicated behavior observed for reinforced concrete structures, in which inelastic deformations are combined with tensile cracking and bond slip. The equation is limited to non-sway columns.

\section{NUMERICAL SIMULATION}

In order to simulate this behavior a non linear finite element software was selected and calibrated with 44 experiments performed by this research group. The required numerical software had to be two-dimensional (membrane elements and trusses) in order to recreate: two-dimensional strainsoftening constitutive relations, distributed cracking, bond-slip, plastic behavior of steel and concrete, the appearance of plastic hinges, $2^{\text {nd }}$ order effects, etc. The software selected was ATENA, Cervenka (1998). The model included a biaxial fracture criteria, tension stiffening, and quadratic iso-parametric finite elements with 4 gauss integration points. In order to not extend the paper too much, the complex task of calibration can be read in Bendito (2006), where an error of $2.03 \%$ was achieved. Hereinafter, this virtual laboratory allowed performing more tests to propose a new equation for the buckling length.

The 2-D finite element software with membranes elements cannot simulate directly the classical rotational spring, because it has only two-dimensional degrees of freedom (u and v). In order to do that, special purpose geometry was created: a column with two elastic beams. These beams 
represent the rotational springs, Figure 1.

A preliminary study to test the geometrical two-dimensional model was developed in three steps in order to verify that the buckling behavior is acceptable.

1) Column and springs (that is, beams) were modeled initially using elastic materials to compare the numerical k-factor with the theoretical elastic solution. Both k-factors were similar to the 2 nd decimal.

2) The second test was accomplished supposing an inelastic behavior for columns but the springs were modeled with zero stiffness. Load-slenderness graphs were obtained to compare with the elastic Euler's hyperbola values. Also normalized load-slenderness curves were created to check coherence in type of concrete and the reinforcement ratio influence. A statement from Broms and Viest (1961) was numerically verified: "an increase in the proportion of the load carried by the reinforcement leads to a more stable column, i.e. highstrength concrete columns, or those with less longitudinal reinforcement ratio tend to be more affected by length". Geometrical model with zero stiffness value for beams shows similar behavior to that of a pinned-pinned column, so they could be used to define the buckling length for different column lengths and different stiffness of beams simulating springs. Load-slenderness curves with beam stiffness equal to zero and inelastic columns will be called "base curves". There was generated a base curve for each parameter combination $\left(\mathrm{f}_{\mathrm{c}}, \mathrm{f}_{\mathrm{y}}\right.$ and $\left.\rho_{\mathrm{g}}\right)$.

3) The third step was to analyze inelastic columns with different elastic stiffness springs. There were found important differences between elastic and inelastic effective length factors (lower k-factor values). This preliminary study made necessary a deeper study of sensitivity to detect the parameters of major influence on the effective length factor. 


\section{SENSITIVITY NUMERICAL STUDY}

The variables that were studied are presented in Table 1.

Both, column and beams had a square section of $30 \mathrm{~cm}$ x $30 \mathrm{~cm}$. The reinforcement was 4 bars, located at each corner of the column in a symmetric distribution. The mechanical reinforcement cover was fixed at $10 \%$ of the height and the width of the section.As it was said in the previous section, a real curve of the critical axial load versus slenderness was obtained for each section configuration with the numerical model for a pinned-pinned column (base curve). This curve improved the elastic Euler's hyperbola, because it includes the non-linearities of the model. It was adjusted with a $5^{\text {th }}$ degree polynomial.

The maximum load under compression was obtained for each parameter using the numerical model and also including the equivalent rotational springs. Substituting this critical axial load in the base curve, the equivalent slenderness was obtained. The inelastic k-factor was obtained from it, $[\mathrm{k}=(\lambda \mathrm{h}) / \mathrm{L}]$. See Figure 2. The hypothesis that the effective length factor of the inelastic, pinned column is equal to unity, i.e. the same as for elastic columns is accepted. Many graphs were generated in the sensitivity study but only some of them are presented in this paper, Figure 3 and Figure 4. From the complete sensitivity study it can be inferred that k-factor increases with the concrete strength and the longitudinal reinforcement ratio, and decreases with the increment of the fixity factor (obvious). Both parameters had the same influence in the inelastic effective length factor, around $35 \%$ and $37 \%$. However, only $1 \%$ of difference is observed when the strength of steel was modified between 400 and $500 \mathrm{MPa}$. So, the steel strength was fixed to $500 \mathrm{MPa}$.

COMPARISON BETWEEN THE NUMERICAL MODEL AND THE DESIGN CODES. 
The inelastic k-factor was compared with the codes ACI-318(2005), the Spanish code EHE (1999), the Euro Code 2 (2004) and with a previous equation proposed by Traver and Bonet (2002). This last equation comes from a 1-D finite element analysis.

It was deduced that for all the cases and for any slenderness, the inelastic k-factor was lower than that obtained using the equation from the ACI and Spanish EHE code. Regarding the EC2 and concerning some of the slenderness, however, the inelastic effective length was higher, Figure 5 and Figure 6.

Higher differences were observed for the lower strength of concrete (f'c), lower reinforcement ratio $\left(\rho_{\mathrm{g}}\right)$ and for the lower stiffness rotational springs $\left(\rho_{1}\right.$ and $\left.\rho_{2}\right)$.

It is important to find out that the buckling coefficient of the ACI and EHE codes does not take into account the reinforcement ratio; hence for different percentages of it, the values of the k-factor are the same. However, the simplified equation of Traver and Bonet (2002), the equation of the Euro Code 2 and the inelastic k-factor change with f'c, reinforcement ratio and the slenderness. The errors are shown in Table 2. Because there are representative differences with respect to all of them: the ACI code (between 37\% and -3\%), with the Spanish code EHE (26\% and $-9.26 \%$ ), with the Euro code 2 (between the $14 \%$ and $-14 \%$ ) and regarding Traver and Bonet (14\% and $-7 \%$ ), it was decided to propose a new equation for the effective length factor for non-sway columns.

\section{EQUATION OF THE INELASTIC EFFECTIVE LENGTH FACTOR}

It is better to adjust the equation in terms of the fixity factors rho (equation 2), which varies between 0 and 1 , whereas the rotational stiffness varies between 0 and infinity. Thereby, the kfactor is calculated in terms of the fixity factors ' $\rho$ ' initially with respect to a fixed slenderness $(\lambda=35)$ in order to include in the main part of the equation only the variables of the strength of 
concrete and the longitudinal reinforcement ratio. Later on, the slenderness will be included using a correcting parameter.

For a particular case of $\mathrm{f}^{\prime}{ }_{\mathrm{c}}=60 \mathrm{MPa}$ and a $2 \%$ of longitudinal reinforcement ratio the procedure to obtain an equation of $\mathrm{k}$ is explained below. A graph of k-rho2 is obtained, with fixed rho1 (not presented for simplicity). The first graph is for $\rho_{1}=0.2$, and the second one is for $\rho_{1}=0.8$.

Only these two graphs are obtained to create initially a very simple equation of $\mathrm{k}$, which is a linear interpolation of $\rho_{2}$.

$$
k=a \rho_{2}+b
$$

But what is very important is that the coefficients "a" and "b" are not constant; they vary with $\rho_{1}$. If the values of "a" and "b" are presented in terms of $\rho_{1}$, it can be inferred that they are also linear functions. These coefficients, shown in Table 3, are obtained from a trend line.

Replacing the values of "a" and "b" in Eq. 4, the following equation is obtained:

$$
k=\left(0.15 \rho_{1}-0.28\right) \rho_{2}+(-0.2817+0.9167)
$$

Simplifying the previous equation, the equation 5 is obtained:

$$
k=0.15 \rho_{1} \rho_{2}-0.28\left(\rho_{1}+\rho_{2}\right)+0.92
$$

The same procedure is performed for each case of longitudinal reinforcement ratio and strength of concrete, reaching the values of $\mathrm{k}$ presented at Table 4 .

\section{Correcting Factor " $\alpha$ ".}

The fixity factors $\rho_{1}$ and $\rho_{2}$ depend on the rotational stiffness of the beams $K_{1}$ and $K_{2}$, the unsupported length $\mathrm{L}$ and the stiffness $\mathrm{E}_{\mathrm{c}} \mathrm{I}_{\mathrm{g}}$ of the column, equation 2 .

In the real behavior of the columns the stiffness E-I is not elastic, because it will vary due to the cracking of concrete, the creep, the reinforcement, etc, but to include a complex equation of EI will 
complicate extremely the method. The influence of $f^{\prime}{ }_{c}, f_{y}$ and $\rho_{g}$ was included in the previous section in the equations of " $k$ ". Hereby, it is necessary complement the previous equations with a correction parameter to include the effect of the geometric slenderness because in the previous step it was fixed to $\lambda=35$.

The equation 2 is reformulated as:

$$
\rho_{i}=\frac{1}{1+\frac{3}{R_{i}}} \quad R_{i}=\frac{K_{i}}{\alpha\left(\frac{E_{c} \cdot I_{g}}{L}\right)}
$$

where " $\alpha$ " is the slenderness correcting factor.

The parameter " $\alpha$ " can be calculated by performing the following steps in sequence, for the other cases of slenderness $(\lambda=20,30,40$ and 50$)$ :

- The values of the fixity factors $\rho_{1}$ and $\rho_{2}$ are analytically replaced in the corresponding equation of Table 4 .

- The value of inelastic k-factor is known because it was previously obtained numerically. In this case, the value of $k$ can be related to only one unknown, the parameter " $\alpha$ ".

- As the equation of " $\mathrm{k}$ " depends on " $\alpha$ " in a quadratic form, an iterative procedure is performed. The first value of " $\alpha$ " will be termed "alpha-trial".

- The values of alpha are adjusted until both values of $\mathrm{k}$ are matched. Doing that, the effect of the last variable $\lambda$ is included in the procedure.

- The values of alpha are obtained in terms of the slenderness. A relationship is obtained: $\alpha=0.04 \lambda-0.40$.

\section{SIMPLIFIED EQUATIONS FOR DESIGN AND CHECKING IN THE CODES.}

In this section, simplified equations valid for implementation in national codes are presented. The equations are valid for normal and high strength concrete both for design and checking. 


\section{Proposed equations for checking.}

The equations for checking are in terms of strength of concrete $f^{\prime} c$, the longitudinal reinforcement ratio, $\rho_{\mathrm{g}}$ and the fixity factors $\rho_{1}$ and $\rho_{2}$, Table 5 .

Comparison between the proposed simplified equation for checking and the exact inelastic k-factor.

Figure 7 compares the proposed equation for checking with the exact inelastic effective length factor, in order to demonstrate that it has better accuracy than that existing in the codes. The errors have been diminished from the initial $14 \%$ until $5.7 \%$.

If some random cases are computed for casual values of slenderness, rotational stiffness, strength of concrete, the maximum error is as low as $1.8 \%$. In conclusion, the proposed equation has a good accuracy for the calculation of the k-factor for inelastic columns and elastic rotational springs.

\section{Proposed equation for design}

The proposed equation for design is simplified in order to not depend on the longitudinal reinforcement ratio. They depend on " $\mathrm{f}_{\mathrm{c}}$ " and $\rho_{1}$ and $\rho_{2}$, Table 6 . Table 7 summarizes the errors for both equations (checking and design). It can be noticed that the average error is $2.6 \%$ for checking and around $7.6 \%$ for design in the safe side, which it improves greatly the existing methods in the codes.

\section{CONCLUSIONS}

The calculation of the effective length factor in real concrete columns is not properly addressed now. The reason is, most of the research to obtain such length assumes a linear elastic material behavior, which is not the case for reinforced concrete. There is no research study prior to the present one that uses 2D non-linear finite element analysis to study the effective length factor.

- It was demonstrated that if the real behavior of the column is modeled, the k-factor is lower than the elastic one. 
- If a sensitivity study is performed, the strength of concrete and the longitudinal reinforcement ratio have the same influence on the inelastic k-factor coefficient, around $35 \%$ and $37 \%$. However the yield stress of steel has not any influence.

- If a comparative study is performed between the numerical model and the different codes, it can be shown that there are representative differences with respect to all of them: the ACI code (between 37\% and -3\%), with the Spanish code EHE (26\% and $-9.26 \%$ ), with the Euro code 2 (between the $14 \%$ and $-14 \%$ ) and regarding Traver and Bonet (14\% and $-7 \%)$. It was decided to propose a new equation for the effective length factor for non-sway columns.

Three types of equations were proposed for the inelastic k-factor: one complete and two simplified (checking and design). It can be noticed that the medium error is $2.6 \%$ for checking and around $7.6 \%$ for design in the safe side, which improves greatly on the existing methods in the codes.

\section{ACKNOWLEDGEMENTS}

The authors wish to express their sincere gratitude to the Spanish "Ministerio de Fomento" for help provided through project 13-12-2001 and "Ministerio de Educación" through BIA2005-255.

\section{APPENDIX I. REFERENCES}

American Concrete Institute (2005). "Building Code Requirements for Structural Concrete and Commentary." ACI 318-05, ACI Committee 318, Farmington Hills, Michigan, USA.

Aristizábal-Ochoa, J.D. (1994). "K-factor for columns in any type of construction: Nonparadoxical approach." J. Struct. Eng., 120(4), 1272-1290. 
Bazant, Z.P., Xiang, Y. (1997). "Inelastic buckling of concrete column in braced frame.” J. Struct. Eng., 123 (5), 634- 642.

Bendito, A. (2006). "Estudio numérico del pandeo inelástico de soportes de hormigón armado intraslacionales", doctoral dissertation, Universitat Jaume I, Castellon, Spain (in Spanish).

Breen J.E., MacGregor J.G. and Pfrang E.O.(1972). "Determination of Effective Length Factors for Slender Concrete Columns", J. Am. Concr. Inst., 69(11), 669-672.

Broms B. and Viest I.M. (1961). "Long Reinforced Concrete Columns: A Symposium" Transactions, J. Struct. Eng., 126(2), 308-400.

Cervenka, V. (1998). “Applied brittle analysis of concrete structures". Proc. 5th Int. Conf. on Fracture Mechanics of Concrete Structures, vol. 4, 1107-1116, publisher Freiburg, Germany.

Cranston, W.B. (1972), "Analysis and design of reinforced concrete columns", Cement and Concrete Association, Research report 20, London, 1972.

Disque, R.O. (1973), “Inelastic K-Factor in Design”, AISC Eng. J., 10(2):33-35.

Duan L., Chen W.F., King W.S., Zhou R.G. and Hu Y.X. (1993), "On effective length factor of framed columns in the ACI building code." ACI Struct. J., 90(2), 135-143.

Duan, L. and Chen, W.F. (1999) "Effective Length Factors of Compression Members”, Structural Engineering Handbook, Ed. Chen Wai-Fah, Boca Raton: CRC Press LLC.

European Committee for Standardization, EC-2. (1991). "Eurocode 2: Design of concrete structures- Part 1: General rules and rules for buildings." ENV-1992-1-1.

EHE (1999), “Instrucción de Hormigón Estructural”, Ministerio de Fomento, Spain.(in spanish).

Furlong R.W. (1998)," Discussion: Inelastic Buckling of Concrete Column in Braced Frame J. Struct. Engrg., Volume 124, Issue 6, pp. 721-722. 
Hu, X.Y., Zhou, R.G., King, W.S., Duan, L., and Chen, W.F. (1993), “On Effective Length Factor of Framed Columns in ACI Code”, ACI Struct. J., 90(2), 135-143.

MacGregor, J.G., Breen, J.E., and Pfrang, E.O. (1970). "Design of slender concrete columns", J. Am. Concr. Inst., 67(1), 6-28.

Traver J., Bonet J.L. (2002), “Cálculo del factor de amplificación de momentos en soportes esbeltos intraslacionales de hormigón armado en flexo-compresión esviada”. Master thesis, Technical University of Valencia, Spain (in spanish).

Shanley, F.R., (1947). "Inelastic column theory”, J. Aero. Sci. 14 (5), 261:268.

Yura, J.A. (1971), “The Effective Length of Columns in Unbraced Frames”. AISC Eng. J., 8(2),3742. 


\section{APENDIX I. NOTATION}

The following symbols are used in this paper:

$\mathrm{k}$-factor $=$ effective length factor

$\mathrm{E}_{\mathrm{c}}=$ elastic modulus of concrete

$\mathrm{I}_{\mathrm{g}}=$ gross moment of inertia

$\mathrm{L}=$ unsupported length of the column

$\mathrm{h}=$ height of the column cross section

$\mathrm{K}_{1}$ and $\mathrm{K}_{2}$ : stiffness of end springs (end restrain condition).

$\mathrm{f}_{\mathrm{c}}=$ cylinder strength of concrete

$\mathrm{f}_{\mathrm{y}}=$ yield stress of steel

$\rho_{\mathrm{i}}=$ fixity factors.

$\alpha=$ slenderness correcting factor

$\lambda=$ geometric slenderness $=\mathrm{L} / \mathrm{h}$ 


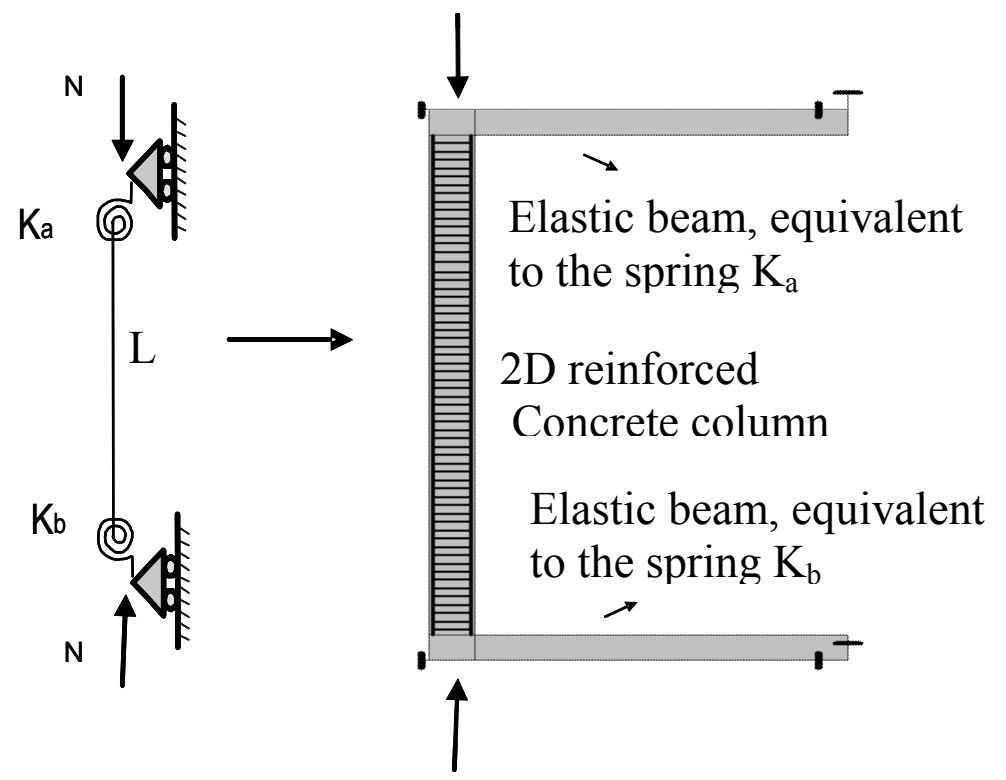

Figure 1. Geometry of the problem. 


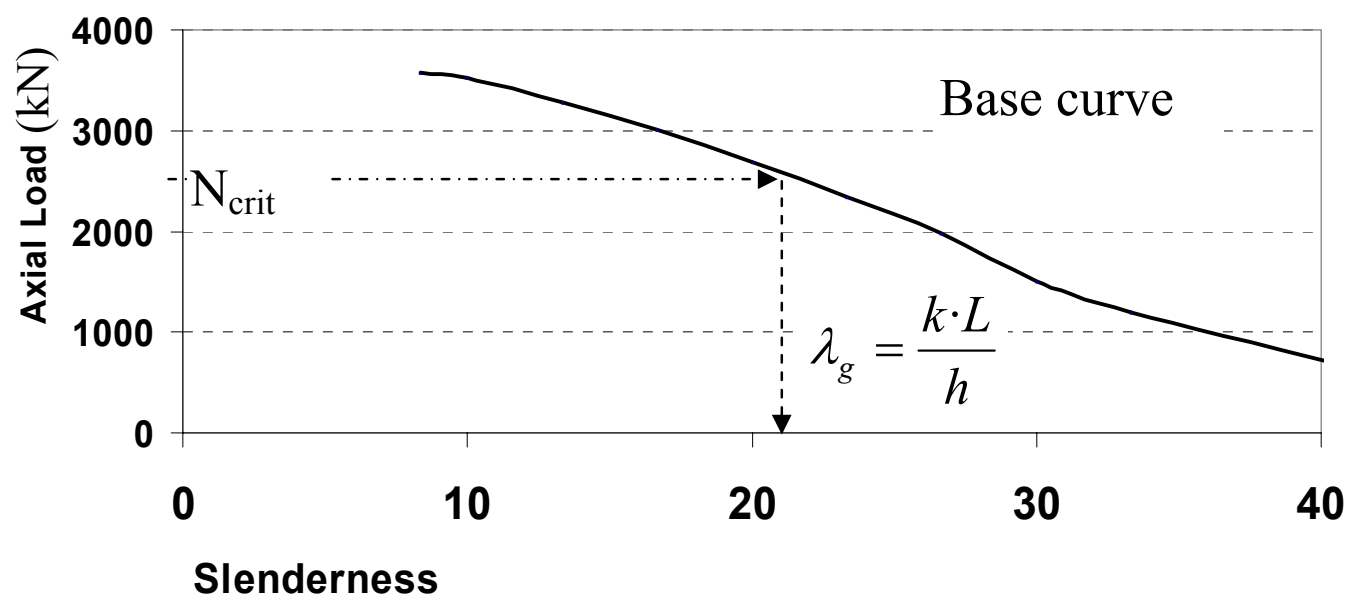

Figure 2. Procedure to obtain the inelastic buckling coefficient. 


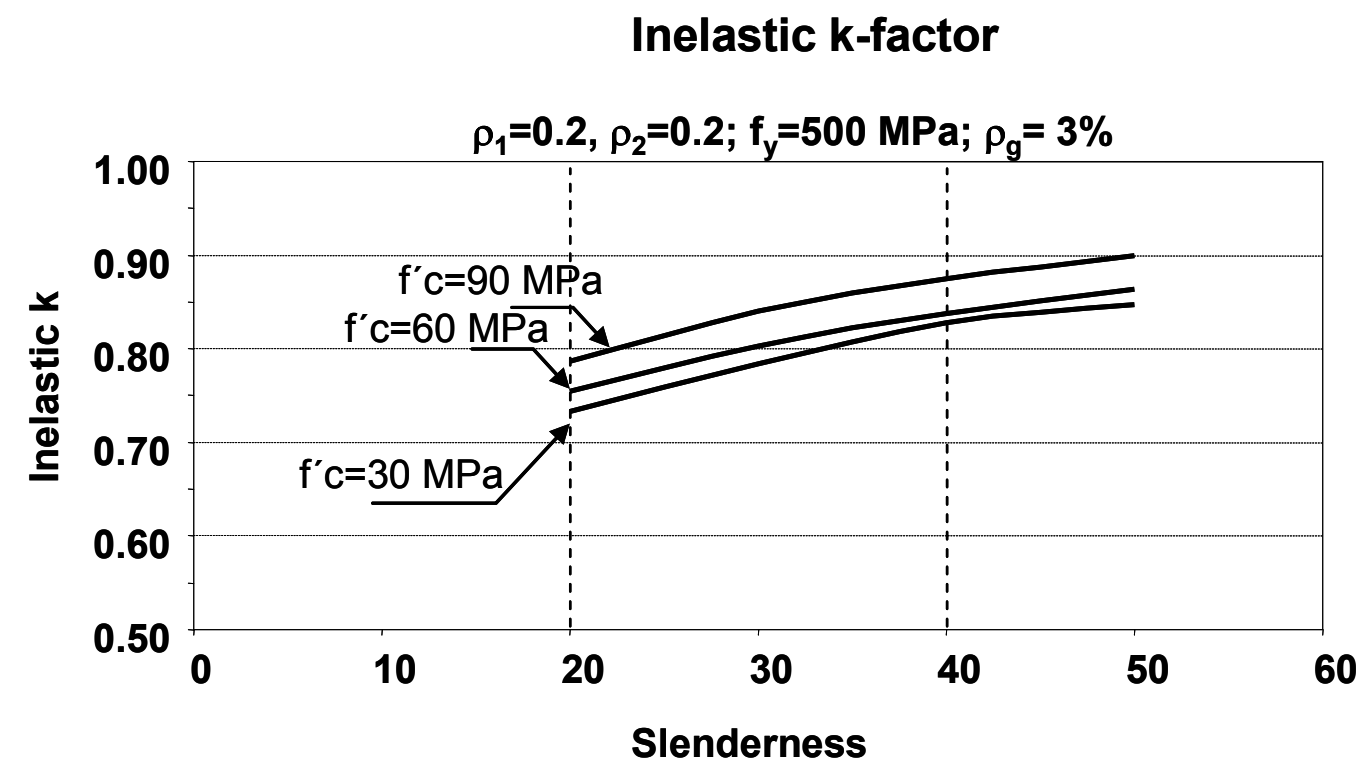

Figure 3. Curve Inelastic $\mathrm{k}-\lambda$ for $\rho_{\mathrm{g}}=3 \%, \mathrm{f}_{\mathrm{y}}=500 \mathrm{MPa}$, changing $\mathrm{f}_{\mathrm{c}}$. 


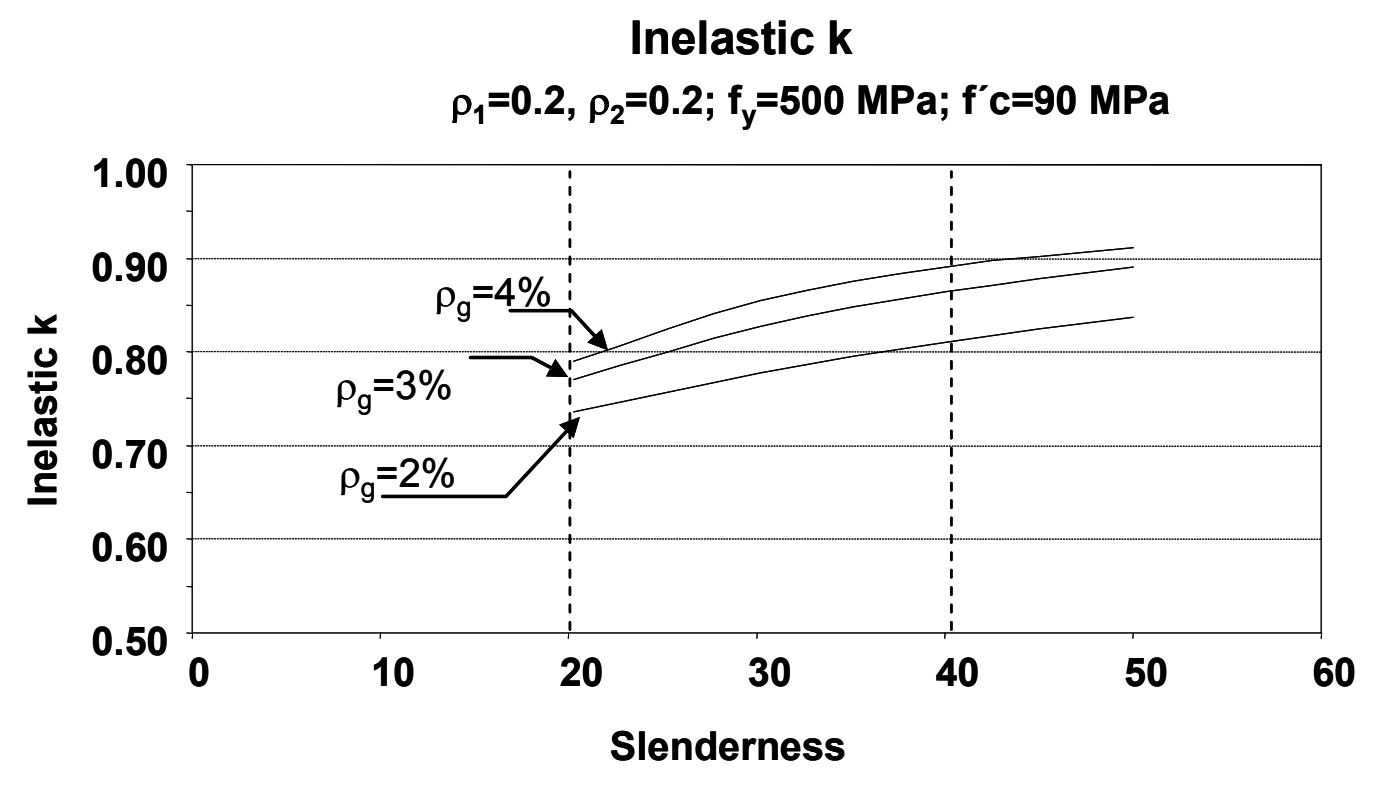

Figure 4. Curve inelastic $\mathrm{k}-\lambda, \rho_{\mathrm{l}}=0.2, \mathrm{f}_{\mathrm{y}}=500 \mathrm{MPa}$, for various $\rho_{\mathrm{g}}$, 


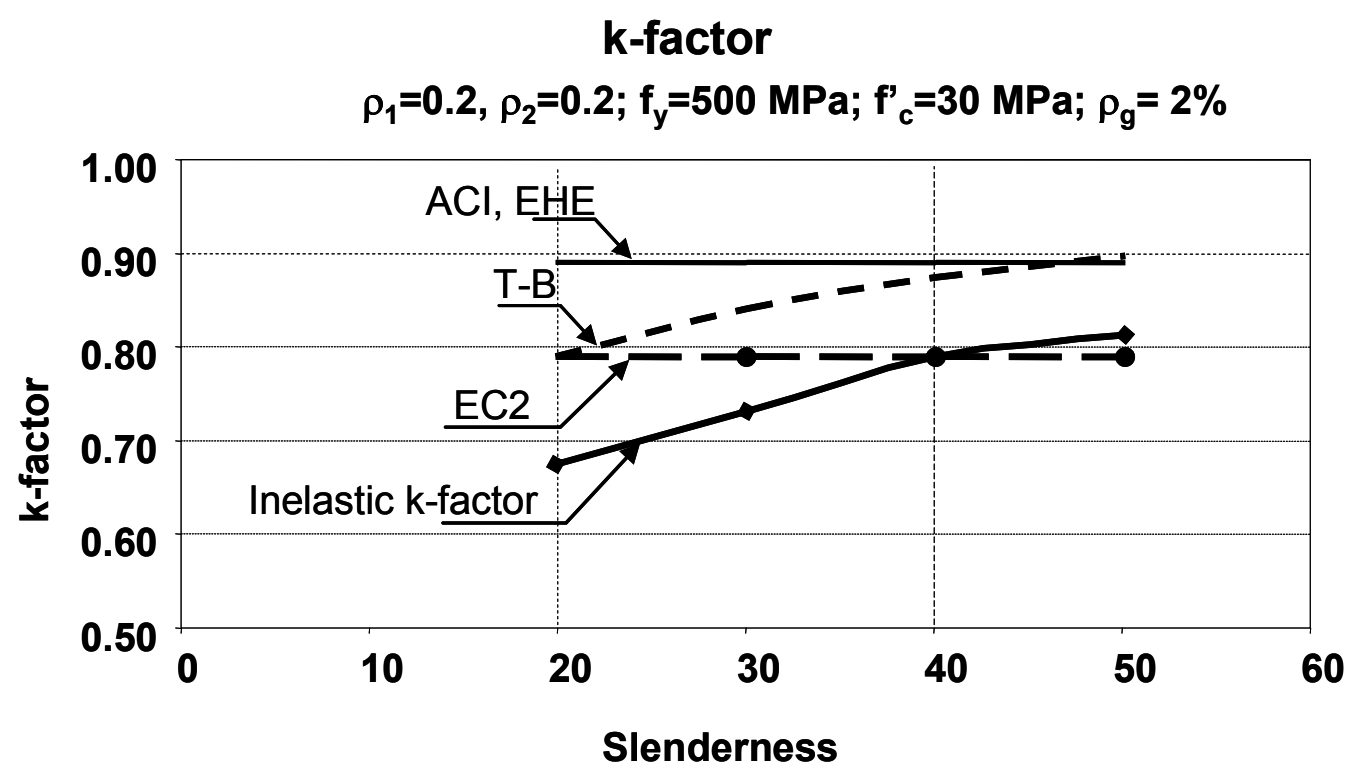

Figure 5. Comparative curves for ACI code, Spanish EHE, Euro code 2 EC2, and Traver and Bonet $\mathrm{T}-\mathrm{B}$, for normal strength concrete 


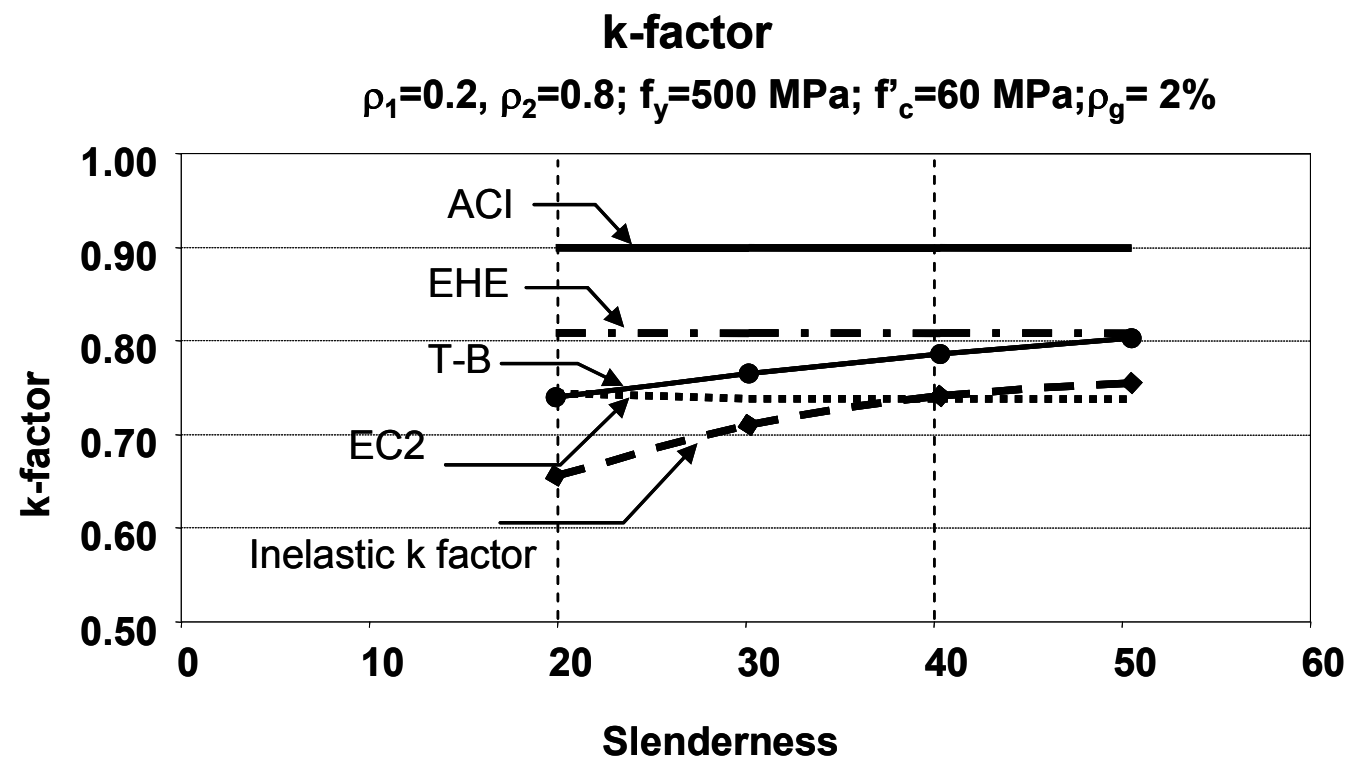

Figure 6. Comparative curves for ACI code, Spanish EHE, Eurocode 2 EC2, and Traver and Bonet $\mathrm{T}-\mathrm{B}$, , for high strength concrete 
k-factor

$\rho 1=0.2, \rho 2=0.8 ;$ fy=500MPa; $2 \%, 60 \mathrm{MPa}$

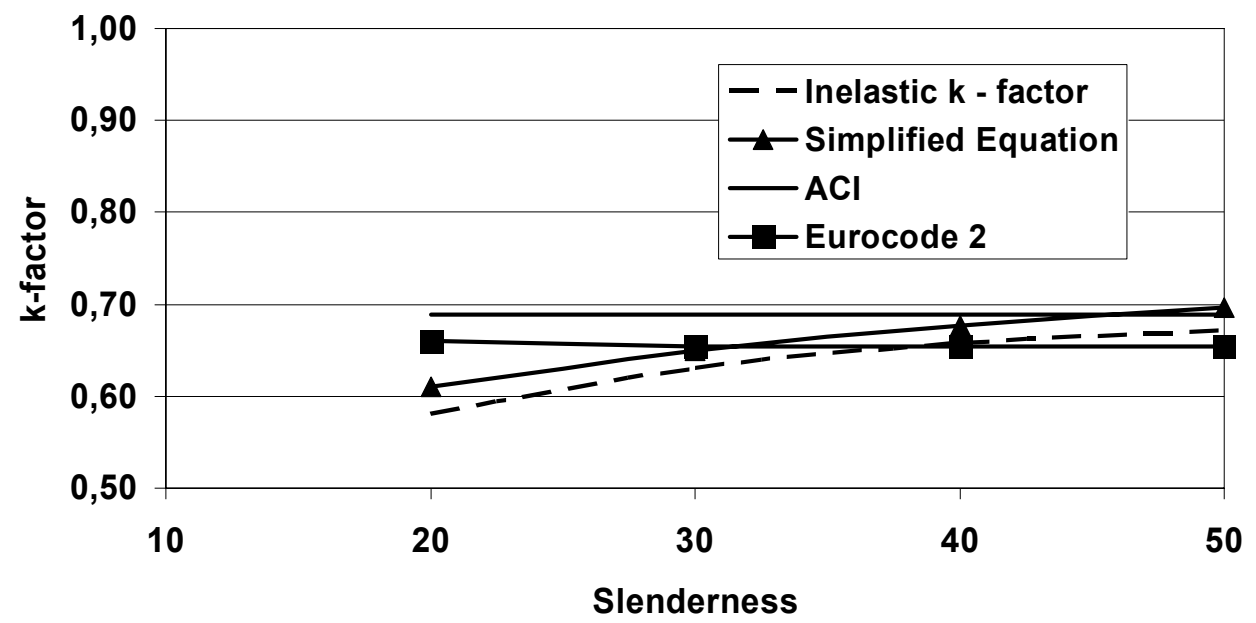

Figure 7. Comparison between the proposed equation for checking and the inelastic k-factor. 


\begin{tabular}{c|c}
\hline PARAMETERS OF STUDY & SCOPE \\
\hline Strength of concrete $\mathbf{f}_{\mathbf{c}}$ & 30,60 and $90 \mathrm{MPa}$ \\
\hline Long. reinforcement ratio $\rho_{\mathbf{g}}$ & $2 \%, 3 \%$ and $4 \%$ \\
\hline Geometric Slenderness $\lambda=\mathbf{L} / \mathbf{h}$ & $20,30,35,40$ and 50 \\
\hline Yield stress of steel, fy & 400 and $500 \mathrm{MPa}$ \\
\hline $\begin{array}{c}\text { Fixity factor of the rotational } \\
\text { springs, } \rho_{\mathbf{1}} \text { and } \rho_{\mathbf{2}}\end{array}$ & $\rho_{1}=0.2$ and $\rho_{2}=0.2$ \\
\cline { 2 - 2 } & $\rho_{1}=0.2$ and $\rho_{2}=0.8$ \\
\cline { 2 - 2 } & $\rho_{\mathbf{1}}=0.8$ and $\rho_{2}=0.8$ \\
\hline
\end{tabular}

Table 1. Parameters of study in the sensitivity analysis. 


\begin{tabular}{|c|c|c|c|c|}
\hline Values & T-B & EHE & ACI & EC2 \\
\hline Maximun & $14.1 \%$ & $26.2 \%$ & $37.7 \%$ & $14.2 \%$ \\
\hline Minimun & $-7.7 \%$ & $-9.2 \%$ & $-3.6 \%$ & $-13.8 \%$ \\
\hline Std. Dev & 0.056 & 0.07 & 0.093 & 0.062 \\
\hline Average & $2.9 \%$ & $5.4 \%$ & $16.7 \%$ & $-1.6 \%$ \\
\hline
\end{tabular}

Table 2. Analysis of errors. 


\begin{tabular}{|c|c|c|}
\hline $\boldsymbol{p}_{1}$ & $\mathbf{a}$ & $\mathbf{b}$ \\
\hline 0.2 & -0.25 & 0.86 \\
\hline 0.8 & -0.16 & 0.69 \\
\hline
\end{tabular}

Table 3. Values of "a" and "b". 


\begin{tabular}{|c|c|}
\hline $\boldsymbol{\rho}_{\mathbf{g}}$ & $\mathbf{f}_{\mathrm{c}}=\mathbf{3 0} \mathbf{~ M P a}$ \\
\hline $2 \%$ & $\mathrm{k}=0.20 \rho 1 \rho 2-0.28(\rho 1+\rho 2)+0.90$ \\
\hline $3 \%$ & $\mathrm{k}=0.20 \rho 1 \rho 2-0.28(\rho 1+\rho 2)+0.92$ \\
\hline $4 \%$ & $\mathrm{k}=0.20 \rho 1 \rho 2-0.28(\rho 1+\rho 2)+0.95$ \\
\hline
\end{tabular}

\begin{tabular}{|c|c|}
\hline$\rho_{\mathrm{g}}$ & $\mathrm{f}_{\mathrm{c}}=60 \mathrm{MPa}$ \\
\hline $2 \%$ & $k=0.15 \rho 1 \rho 2-0.28(\rho 1+\rho 2)+0.92$ \\
\hline $3 \%$ & $\mathrm{~K}=0.15 \rho 1 \rho 2-0.28(\rho 1+\rho 2)+0.95$ \\
\hline $4 \%$ & $K=0.15 \rho 1 \rho 2-0.28(\rho 1+\rho 2)+0.97$ \\
\hline & \\
\hline$\rho_{\mathrm{g}}$ & $\mathrm{f}_{\mathrm{c}}^{\prime}=90 \mathrm{MPa}$ \\
\hline $2 \%$ & $K=0.15 \rho 1 \rho 2-0.28(\rho 1+\rho 2)+0.95$ \\
\hline $3 \%$ & $K=0.15 \rho 1 \rho 2-0.28(\rho 1+\rho 2)+0.98$ \\
\hline $4 \%$ & $k=0.15 \rho 1 \rho 2-0.28(\rho 1+\rho 2)+1$ \\
\hline
\end{tabular}

Table 4. Equations of the inelastic k-factor with respect to the stiffness factors, with fy=500MPa. 


\begin{tabular}{c|c}
\hline $\begin{array}{c}\text { Normal Strength Concrete } \\
\text { (up to 50 MPa) }\end{array}$ & $\begin{array}{c}\mathbf{k}=\mathbf{0 . 2} \rho_{\mathbf{1}} \rho_{\mathbf{2}} \mathbf{- 0 . 2 8}\left(\rho_{\mathbf{1}}+\rho_{\mathbf{2}}\right)+\mathbf{A} \\
\text { where } \mathrm{A}=0.025 \rho_{\mathrm{g}}+0.85<=1\end{array}$ \\
\hline High Strength Concrete & $\mathbf{k}=\mathbf{0 . 1 5} \rho_{\mathbf{1}} \rho_{\mathbf{2}} \mathbf{- 0 . 2 8}\left(\rho_{\mathbf{1}}+\rho_{\mathbf{2}}\right)+\mathbf{B}$ \\
(between 50 and $90 \mathrm{MPa}$ ) & $\mathrm{B}=0.03 \rho_{g}+\mathrm{f}_{\mathrm{c}} / 70<=1$ \\
(higher than $90 \mathrm{MPa}$ ) & $\mathrm{B}=0.025 \rho_{\mathrm{g}}+\mathrm{f}_{\mathrm{d}} / 100<=1$ \\
\hline \multicolumn{2}{c}{ where $\rho_{\mathrm{g}}$ is the longitudinal reinforcement ratio } \\
\hline Slenderness correcting factor & $\alpha=0.04 \lambda-0.4$ \\
\hline
\end{tabular}

Table 5. Proposed equation of k-factor for checking. 


\begin{tabular}{c|c}
\hline Normal Strength Concrete & $\mathbf{k}=\mathbf{0 . 2} \rho_{\mathbf{1}} \rho_{\mathbf{2}} \mathbf{- 0 . 2 8}\left(\rho_{1}+\rho_{2}\right)+\mathbf{0 . 9 5}$ \\
\hline High Strength Concrete & $\mathbf{k}=\mathbf{0 . 1 5} \rho_{\mathbf{1}} \rho_{\mathbf{2}} \mathbf{- 0 . 2 8}\left(\rho_{1}+\rho_{2}\right)+\mathbf{1}$ \\
\hline \multicolumn{2}{c|}{ where $\rho_{g}$ is the longitudinal reinforcement ratio } \\
\hline Slenderness correcting factor & $\alpha=0.04 \lambda-0.4$ \\
\hline & $\lambda$ is the geometric slenderness \\
\hline
\end{tabular}

Table 6. Proposed equation for design. 


\begin{tabular}{|c|c|c|}
\hline Values & $\begin{array}{c}\text { Error } \\
\text { for } \\
\text { checking }\end{array}$ & $\begin{array}{c}\text { Error } \\
\text { for } \\
\text { design }\end{array}$ \\
\hline Maximum & $6.19 \%$ & $19.02 \%$ \\
\hline Minimum & $0.00 \%$ & $0.00 \%$ \\
\hline Typical Dev & $0.02 \%$ & $0.04 \%$ \\
\hline Average & $2.60 \%$ & $7.63 \%$ \\
\hline
\end{tabular}

Table 7. Error for both methods. 
Figure 1. Geometry of the problem.

Figure 2. Procedure to obtain the inelastic buckling coefficient.

Figure 3. Curve Inelastic $\mathrm{k}-\lambda$ for $\rho_{\mathrm{g}}=3 \%$, fy=500 $\mathrm{MPa}$, changing fc.

Figure 4. Curve Inelastic $\mathrm{k}-\lambda$ for $\rho_{\mathrm{g}}=4 \%, \mathrm{fy}=500 \mathrm{MPa}$, changing fc.

Figure 5. Comparative curves for ACI code, Spanish EHE, Eurocode 2 EC2, and Traver and Bonet $\mathrm{T}-\mathrm{B}$, for normal strength concrete

Figure 6. Comparative curves for ACI code, Spanish EHE, Eurocode 2 EC2, and Traver and Bonet $\mathrm{T}-\mathrm{B}$, , for high strength concrete

Figure 7. Comparison between the proposed equation for checking and the inelastic k-factor. 